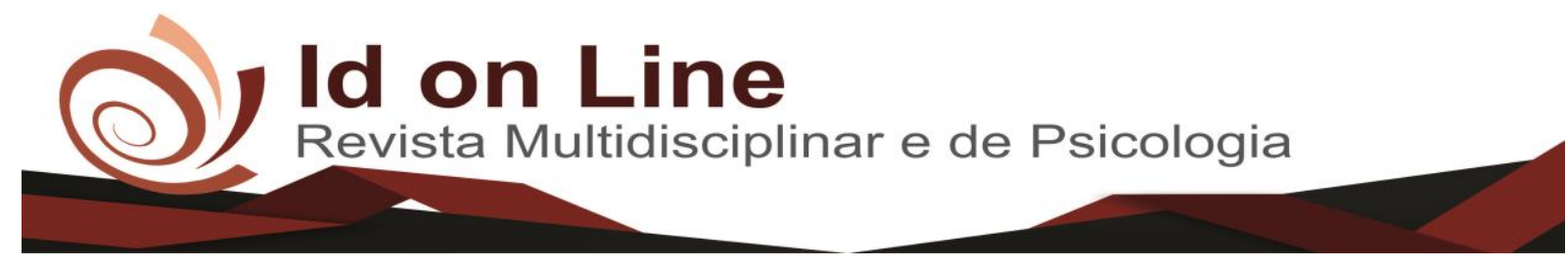

DOI:

Comment

\title{
A Importância da Leitura nos anos iniciais do Ensino Fundamental: Processos e Desafios Pedagógicos
}

\author{
Witalla Dayane Silva Monteiro Neto ${ }^{1}$; Pedro Fernando dos Santos ${ }^{2}$; Maria do Socorro Cecílio Sobral ${ }^{3}$
}

\begin{abstract}
Resumo: O presente artigo tem por objetivo apresentar os desafios encontrados pelos profissionais da educação no processo de ensino aprendizagem da leitura nos anos iniciais do ensino fundamental. O texto contará em sua estrutura, os Parâmetros Curriculares Nacionais da Língua portuguesa, que foi referência chave para o desencadeamento da construção do artigo, assim como autores voltados ao assunto estudado. Exemplos de realidades vivenciadas em sala de aula, que viriam ao prejudicar o processo leitor do aluno, visto que o texto explicará uma variedade de fatores voltados a essa realidade, que vai desde um simples espaço de leitura, como o tipo de leitura oferecido a criança. O texto aborda princípios que os professores de língua portuguesa devem tomar como exemplo para o seu dia a dia em sala de aula, na construção de novos leitores. Destaca-se a importância da leitura na idade certa, em decorrência de fatores que implicará no desenvolvimento leitor do aluno, que vai desde uma simples interpretação de texto, como capacidades cognitivas e organizações de ideias em linhas de pensamentos, assim como aquisição de novos conhecimentos e uma visão de mundos diferentes. Ênfase no objeto de estudo, O LIVRO, que mesmo com os avanços tecnológicos, o livro continua sendo a principal ferramenta para a formação de futuros leitores .Portanto, o artigo deixa bem claro que a leitura e essencial no processo de formação do cidadão, e começá-la desde ceda, na idade, e no tempo escolar certo o aluno terá mais rendimento na sua construção social.
\end{abstract}

Palavras-Chave: Leitura. Ensino Fundamental. Processos. Desafios.

\section{The Importance of Reading in the Early Years of Elementary School: Processes and Pedagogical Challenges}

\begin{abstract}
This article aims to present the challenges encountered by education professionals in the teaching process reading learning in the early years of elementary school. The text will contain in its structure, the National Curriculum Parameters of the Portuguese Language, which was a key reference for triggering the construction of the article, as well as authors focused on the subject studied. Examples of realities experienced in the classroom, which would damage the student's reading process, as the text will explain a variety of factors related to this reality, ranging from a simple reading space, such as the type of reading offered to the child. . The text discusses principles that Portuguese language teachers should take as an example for their daily life in the classroom, in the construction of new readers. We highlight the importance of reading at the right age, due to factors that will imply the student's development, ranging from a simple interpretation of text, such as cognitive abilities and organization of ideas in thought lines, as well as the acquisition of new knowledge. and a view of different worlds. Emphasis on the object of study, THE BOOK, that even with technological advances, the book remains the main tool for the formation of future readers. Therefore, the article makes it clear that reading is essential in the process of citizen formation, and start it from the beginning, at the age, and at the right school time, the student will have more income in his social construction.
\end{abstract}

Keywords: Reading. Elementary School. Processes. Challenges.

\footnotetext{
${ }^{1}$ Faculdade de Ciências Humanas do Sertão Central (FACHUSC). dayanne_monteiro3@ hotmail.com;

${ }^{2}$ Faculdade de Ciências Humanas do Sertão Central (FACHUSC).pedrinho_quilombola@ hotmail.com;

${ }^{3}$ Faculdade de Ciências Humanas do Sertão Central (FACHUSC). socorrosobral@bol.com.br.
} 


\section{Introdução}

O processo leitor nos Anos Iniciais do Ensino Fundamental, deve ser realizado de maneira diversificada, analisando-se cada percalço encontrado pelo professor de português no ambiente escolar. O presente artigo tem a finalidade de apresentar os desafios encontrados pelos educadores, desse nível de escolaridade, no processo de ensino aprendizagem voltados à leitura.

Observa-se que a arte da leitura é o processo de formação do cidadão, que começa desde cedo, passando por esse fator essencial que a leitura.

Hoje no mundo em que vivemos, a leitura está muito presente, e a partir do momento em que o aluno começa a desenvolver o processo de ler, desde simples palavras, como, um livro que lhe chame atenção, começa a encontrar-se na sociedade em que vive. A partir do momento em que, qualquer espaço que a criança olha, ela observa que sempre terá uma sílaba que ela possa juntar, uma palavra simples que ela possa ler, ou até mesmo uma frase na qual ela começa a descobrir seu significado, ela inicia um reconhecimento do seu contexto social.

Mas tal estímulo, só acontece quando essa vivência prática da leitura, ocorra dentro da sala de aula, com professores especializado na área, e com a genialidade de sempre que puder modificar sua aula, buscando estratégias, para desenvolver de maneira satisfatória o processo leitor do aluno.

$\mathrm{Na}$ fundamentação teórica, encontra-se além de autores como Ferreiro e Teberosky (1999), Cagliari (2005) e Solé (1999), que tem uma sua concepção sobre os desafios no processo ensino leitor, como o Parâmetro Curricular Nacional da Língua Portuguesa -PCN, se serviu como objeto maior de estudo para a construção do artigo. Visto que esse assunto já é bastante conhecido e discutido por muitos.

No decorrer do texto, apontará vários percalços encontrados pelos professores de língua portuguesa, que vai desde a forma em que o professor trabalha, como, a maneira de que esse alunos está sendo instigado a viver essa nova realidade no ensino fundamental anos iniciais, assim como seu estímulo fora da escola, através do empréstimo de livros e da motivação familiar. É aí onde se faz valer o lema, que família e escola devem andar juntas.

O presente artigo foi desenvolvido através de uma indagação sobre como e quais são os desafios encontrados pelos professores no processo leitor do aluno. E o texto vem com essa resolução de maneira clara e concisa de que é desafiador, mas deslumbrante quando o resultado 
chega de maneira espetacular. Pois apresenta em sua estrutura uma pesquisa qualitativa, e que, mediante os fatos e realidades encontradas hoje, dentro de vários fatores vivenciados pelos aluno.

\section{Fundamentação Teórica}

\section{Desafios da leitura nos anos iniciais do Ensino Fundamental}

A leitura é uma aptidão essencial no processo de formação do cidadão, por está presente em todos os momentos de sua prática social. Mas não basta apenas saber ler, mas fazer um bom uso da leitura, ou seja, ser um bom leitor. A instituição de ensino, na grande maioria das vezes é responsável pela formação dos leitores e isso ocorre a partir dos Anos Iniciais do Ensino Fundamental.

Nos últimos anos aparentemente, observa-se que os professores do Ensino Fundamental entraram em consenso sobre a necessidade de se trabalhar a leitura com textos literários. Onde muitos educadores dedicam boa parte do tempo didático a atividades de leitura, empréstimo de livros, contações de histórias, roda de leituras e muitos outros aspectos relacionados ao processo de aprendizagem da leitura do aluno, obtendo como estratégias o hábito a leitura.

Entretanto, essas mudanças ainda não correspondem a uma significativa melhoria na compreensão leitora e avanços em relação ao entender o que se leu, além da qualidade dos textos escritos pelos alunos. De acordo com os Parâmetros Curriculares Nacionais de Língua Portuguesa (1997):

[...] "É preciso superar algumas concepções sobre o aprendizado inicial da leitura e da escrita. A principal delas é a de que ler é simplesmente decodificar, converter letras em sons, sendo a compreensão consequência dessa ação. Por conta dessa concepção equivocada a escola vem produzindo grande quantidade de leitores capazes de decodificar qualquer texto, mas com enormes dificuldades para compreender o que tentam ler. Não se deve ensinar a ler por meio de práticas centradas na decodificação, é preciso oferecer aos alunos inúmeras oportunidades de aprenderem a ler usando os procedimentos que os bons leitores utilizam. Para aprender a ler, portanto, é preciso interagir com diversos textos escritos; é preciso valorizar o conhecimento que já se teve e o que é apresentado pelo texto, recebendo incentivo e ajuda de leitores experientes". (PCN,1997, p. 55-57).

Observa-se que o professor deve conhecer sua turma e observar o nível de aprendizagem do seu aluno, ocasionando a identificação de atividades e maneiras para que a 
mesma venha a desenvolver a leitura, que vá desde o alfabeto móvel, até a exploração de frases, textos, livros entre outros, possibilitando ao aluno o entendimento de como se pronuncia e como são escritas das palavras.

A leitura diversificada é uma grande estratégia ao que se diz respeito no processo de leitura, pois ao mesmo tempo em que textos diferentes são colocados à disposição do aluno, o mesmo pode imaginar-se dentro do mundo da leitura e assim ter um melhor proveito e um bom desempenho em suas futuras atividades de leitura.

O aprendizado da leitura é um grande desafio tanto na escola como na sociedade, mas, atualmente nas escolas, a preocupação é ensinar o aluno a escrever o que está na lousa, não tendo o sentido e o menor interesse pelo que se faz. Isso faz com que ocorra um retrocesso no processo de aprendizagem leitora do aluno, se limitando apenas a realizar as atividades concedidas pelo professor, que na maioria das vezes usam o tempo como inimigo para a realização de uma atividade diversificada em atribuição da leitura, mesmo que na minoria dos casos, isso ocorra em muitas realidades de sala.

Segundo Ferreiro e Teberosky (1999, p.23) "A leitura é um ato 'global' e 'ideovisual” [...] Não importa qual seja a dificuldade auditiva daquilo que se aprende, posto que a leitura é uma tarefa fundamental visual. No ponto de vista das autoras citadas, a leitura para a criança é um momento pelo qual ela se sinta bem e tenha o prazer no que está fazendo, onde muitas crianças pegam um livro para ler, mesmo que de maneira não convencional, e a primeira coisa que olham é a espessura, e a ilustração da capa, não levando em conta as informações que vão adquirir ao longo da leitura.

Entretanto, mesmo o aluno tendo um maior interesse em relação ao livro, e um aumento na quantidade de livros a sua disposição, tanto nas escolas, como nas famílias, ainda não quer dizer que se tenha uma melhoria na compreensão leitora, nem avanços significativos na qualidade de textos escritos pelos alunos, pois para gostar de ler, é preciso ler bem. E para ler bem, é necessário ter diante si além de bons livros, situações que favoreçam um bom trabalho ativo de construção de sentido do texto, em decorrência da leitura.

$\mathrm{O}$ ato de aprender a ler, é um desafio encontrado por todas as crianças nas fases iniciais de sua escolarização, isto porque o mundo é dominado por informações escritas. Dessa forma, acredita-se que a leitura é uma prática social, pois segundo o PCN- Parâmetro Curricular Nacional de Língua Portuguesa, 
[...] “A leitura, como prática social, é sempre um meio, nunca um fim. Ler é resposta a um objetivo, a uma necessidade pessoal. Fora da escola, não se lê só para aprender a ler, não se lê de uma única forma, não se decodifica palavra por palavra, não se responde a perguntas de verificação do entendimento preenchendo fichas exaustivas, não se faz desenho sobre o que mais gostou e raramente se lê em voz alta. Isso não significa que na escola não se possa eventualmente responder a perguntas sobre a leitura, de vez em quando desenhar o que o texto lido sugere, ou ler em voz alta quando necessário. No entanto, uma prática constante de leitura não significa a repetição infindável dessas atividades escolares". (BRASIL, 1997, p.43).

Observa-se primeiramente, que, para a criança que convive diariamente com verificação da prática escrita no seu dia a dia, leitura de palavras, feita com grande variedade e quantidade de letras, pode facilitar o processo leitor, assim como não ser possível para aquelas que ainda não adquiriram o entendimento do que seja a leitura.

É nessa concepção que Cagliari nos fala, que,

[...] "Ler é decifrar e buscar informações. Já se sabe que o segredo da alfabetização é a leitura. Alfabetizar é, na sua essência, ensinar alguém a ler, ou seja, a decifrar a escrita. Escrever é em decorrência desse conhecimento e não o inverso. Na prática escolar, parte-se sempre do pressuposto de que o aluno já sabe decifrar a escrita, por isso o termo "leitura" adquire outro sentido. Trata-se então da leitura para conhecer o texto escrito. Na alfabetização, a leitura como decifração é o objeto maior a ser atingido." (2005, p.312).

Na prática escolar, para os alunos adquirirem o interesse à leitura, é necessário que os mesmos desenvolvam a disposição em estudar, desencadeando uma reação em cima de uma ação rotineira, buscando aperfeiçoar a sua leitura, já que esta contribui para o processo de ensino aprendizagem, no ensino fundamental. Mediante todo esse processo, o avanço na aprendizagem em função da leitura ocorrerá de maneira contextualizada e gradativa, se a escola valorizar a leitura, através de condições e estratégias para o aluno desenvolvê-la.

Nesse sentido Solé (1999) aconselha que:

[...] "Muitos alunos talvez não tenham muitas oportunidades fora da escola, de familiarizar-se com a leitura; talvez não vejam muitos adultos lendo; talvez ninguém lhes leia livros com frequência. A escola não pode compensar as injustiças e as desigualdades sociais que nos assolam, mas pode fazer muito para evitar que sejam acirradas em seu interior. Ajudar os alunos a ler, a fazer com que se interessem pela leitura, e dotá-los de um instrumento de aculturação e de tomada de consciência cuja funcionalidade escapa dos limites da instituição. (1999, p. 51). 
Quando as crianças não lêem em seu ambiente familiar, ou simplesmente não saberem ler. A escola como seu papel de formadora deve oportunizar recursos para que a leitura aconteça de maneira fluida, pois a criança tendo a oportunidade de ler sem que alguém fique perguntando o que estão entendendo, facilita o contato com o objeto de estudo, ocasionando de maneira espontânea o processo leitor. Porém é preciso saber que quanto mais a escola facilita o processo de construção do conhecimento da leitura, mas vislumbramos fica o espaço, onde o desempenho do aluno de modo consequente ficará melhor.

Visto que, quando o processo leitor ocorre de maneira correta, obtendo sucesso na aprendizagem do aluno, é importante destacar que pontos positivos ocorreram no processo leitor do aluno, onde consequentemente ocorrerá maior facilidade em interpretação textual; maior cognição para compreensão e organização em coerência com uma linha de pensamento; enriquecimento do vocabulário com capacidade de argumentação em uma visão crítica; aquisição de novos conhecimentos e memorização de situações em ações em diferentes contextos;

Em decorrência dos avanços tecnológicos, e sua reflexão no ambiente escolar, o livro ainda continua sendo o principal objeto de estudo, no processo de aprendizagem e leitor dos alunos. E ao estimular o interesse por livros no seu cotidiano é, uma atitude que contribui para fomentar ainda mais o hábito da leitura, visto que o livro fala e a alma responde, permitindo que essa sensação faça parte da vida de futuros leitores é essencial.

\section{Metodologia}

O presente artigo foi desenvolvido a partir de uma pesquisa qualitativa, de origem objetiva e concisa, onde busca informar e os percalços na aprendizagem da leitura nos Anos Iniciais do Ensino Fundamental e os problemas enfrentados pelos professores da Língua Portuguesa.

A segmentação e construção do artigo contêm também estudo e citações baseados em autores renomados no assunto em questão, como, Ferreiro e Teberosky (1999), Cagliari (2005), Solé (1999), entre outros. O conteúdo teve como embasamento os PCNs de Língua Portuguesa, que foi um dos pontos chave e um ótimo objeto de estudo a ser analisado. 


\section{Resultados e discussões}

Constatou-se, que hoje, a questão da leitura é bastante debatida na educação, tanto em sala de aula, como no ambiente de formação de professores. E ao enfatizar esse processo leitor do aluno o professor se depara com muitos aspectos decorrentes da sua realidade de sala e de onde o seu aluno está inserido.

E nesse sentido, descobrir e possibilitar meios no processo de leitura no anos iniciais do ensino fundamental, e como se dará esse processo enquanto professor de língua Portuguesa como formador de alunos leitores. E disponibilizar também, recursos de apoio nesse processo de formação.

Verificou-se que desafios encontrados pelos professores no processo de leitura na segunda fase de ensino encontra-se como uma indagação presente em todos os âmbitos escolares que utilizam da Língua Portuguesa como mecanismo para formar alunos leitores na fase certa.

Assim considerou-se que professor deve ser o profissional a buscar posturas que sejam eficientes no processo ensino e aprendizagem, tais posturas facilitem uma adaptação no currículo voltada tão somente para a necessidade específica do aluno, que pode ser um transtorno ou distúrbio que pode ou não ser corrigido, avaliado e tratado, mas que pode ter resultados valiosos quanto a diminuição das dificuldades e também em aspectos de comportamento.

Constatou-se também que um dos aspectos importantes no ensino da leitura para obtenção de resultados positivos é o incentivo à leitura de textos e livros. Começando com a leitura de imagens, letras, números e palavras que são signos extremamente presentes na sua aprendizagem, pode ser o início de uma vida saudavelmente leitora, com desejo pelo aprendizado e pelo conhecimento.

\section{Considerações Finais}

A leitura é uma das ferramentas fundamentais no processo de ensino aprendizagem, ela faz com que o aluno se encontre no mundo em que vive. O mundo hoje é rodeado de 
informações, e a leitura é o único intermédio para se o cidadão se situar na sociedade.

O texto traz consigo informações bastante relevantes sobre o processo de ensino a leitura nos anos iniciais do ensino fundamental, a fim de enfatizar os processos de desafios a respeito do mesmo. Existem muitas dificuldades encontradas pelos professores para a realização desse processo de leitura, que vai desde o espaço de ensino, como ao próprio professor e sua prática em sala de aula.

É importante ressaltar que o texto deixa uma reflexão aos educadores do ensino fundamental, que vivencia o processo de ensino a leitura, onde ao apontar os desafios em relação à leitura, o mesmo deve procurar soluções ou meios diversificados de se trabalhar com o aluno, para se chegar ao resultado almejado. O ensino a leitura não é fácil, e isso todo mundo sabe mais o professor de língua portuguesa, tem o PCN como instrumento de estudo para a prática em sala de aula, que ao informar sobre os percalços enfrentados, ao mesmo tempo disponibiliza informações e recursos para desencadear a leitura na aprendizagem do aluno.

O Parâmetro Curricular Nacional - PCN de Língua Portuguesa foi objeto de estudo para a realização desse artigo, junto a autores a especializados no tema, como Cagliari, Ferreiro, Solé, dentre outros. Por tanto é de grande valia, adaptar a realidade de sala em prol de um bom desenvolvimento educacional, com ênfase no processo leitor do aluno, e procurar recursos, assim como estratégias para a realização do mesmo. Visto que é através da leitura que a criança começa a enxergar o mundo através de suas informações presente em cada espaço de sua vivência.

\section{Referências}

BRASIL, Secretaria de Educação Fundamental. Parâmetros Curriculares Nacionais: Língua Portuguesa/Secretaria de Educação Fundamental. Brasília: MEC/SEF, 1997.

CAGLIARI, Luiz Carlos. Alfabetização e linguística. São Paulo: Scipione, 2005 Ferreiro (1999

FERREIRO, Emília, TEBEROSKY, Ana- Psicogênese da Língua Escrita- Tradução de Diana Myriam Lichtenstein, Liana Di Marco, Mário Corso.- Porto Alegre: Artmed, 1999. https://novaescola.org.br/conteudo/573/desafios-da-formacao-de-leitores-na-escola. acesso em $26 / 09 / 2019$ 
https://www.google.com/search?q=dasfios+encontrados+no+processo+leitor+do+alno\&oq=d asfios+encontrados+no+processo+leitor++do+alno\&aqs=chrome..69i57.33550j1j8\&sourceid $=$ chrome\&ie $=U T F-8$. Acesso em 26/09/2019.

SOLÉ, Isabel. Estratégias de Leitura; trad. Claudia Schilling. 6 ed. Porto Alegre: ARTMED,1999.

\section{Como citar este artigo (Formato ABNT):}

MONTEIRO NETO, Witalla Dayane Silva; SANTOS, Pedro Fernando dos; SOBRAL, Maria do Socorro Cecílio. A Importância da Leitura nos anos iniciais do Ensino Fundamental: Processos e Desafios Pedagógicos. Id on Line Rev.Mult. Psic., Dezembro/2019, vol.13, n.48, p. 387-395. ISSN: 1981-1179.

Recebido: $23 / 11 / 2019$

Aceito: 29/11/2019 